\title{
It matters how we do it: A review of best practices of Observed Structured Clinical Examination in pharmacy education
}

\author{
Ejaz Cheema 1, Majid Ali 2,3 \\ 1 School of Pharmacy, University of Birmingham, Birmingham, United Kingdom \\ 2 College of Pharmacy, Batterjee Medical College, Jeddah, Saudi Arabia \\ 3 Faculty of Health and Medical Sciences, University of Adelaide, Australia
}

Keywords

Pharmacy

Skills assessment

Performance-based assessment

OSCE

\author{
Correspondence \\ Ejaz Cheema \\ School of Pharmacy \\ University of Birmingham \\ Birmingham \\ United Kingdom \\ B15 2TT \\ E.Cheema@bham.ac.uk
}

\begin{abstract}
Objective: Since the introduction of the Observed Structured Clinical Examination (OSCE) in medical education more than four decades ago, OSCEs have been adopted by a majority of healthcare professional education programmes, including pharmacy. This article aims to review the best practices as well as explore novel approaches to the use of OSCE in pharmacy education. Method: As with any assessment method, the development of OSCE stations starts with blueprinting. Personnel involved in the OSCE are briefed and adequately trained, based on their expertise and prior experience to ensure the efficient running of the OSCE as well as help maintain the reliability and validity of the assessment process. Conclusion: The OSCE assesses a range of clinical and communication skills, yet it is resource-intensive and requires extensive planning. However, it must be considered an important and essential means to develop and assess the skills required by the pharmacy graduates for safe future practice.
\end{abstract}

\section{Introduction}

The practice of pharmacy has evolved significantly over the past few decades and continues to evolve in conjunction with patients' expectations. These expectations have gradually moved pharmacists from the traditional role of dispensing to more patient-oriented roles (Toklu \& Hussain, 2013). This shift in pharmacists' professional role necessitates the change in learning and assessment at pharmacy schools to better equip the graduates. Since the introduction of the Observed Structured Clinical Examination (OSCE) in medical education in 1975 (Harden, \& Gleeson, 1979), it has been adopted by the majority of healthcare professional education programmes, including pharmacy, and has increasingly gained worldwide popularity at both undergraduate and postgraduate levels. Khan and authors (2013) define OSCE as 'An assessment tool based on the principles of objectivity and standardisation, in which the candidates move through a series of time-limited stations in a circuit for the purpose of assessment of professional performance in a simulated environment. At each station, candidates are assessed and marked against standardised scoring rubrics by trained assessors'.

An OSCE usually consists of several simulated stations with students rotating in a round-robin format until all stations have been attempted. Within these simulated clinical situations commonly referred to as stations, students are expected to perform a clinical task or manage a standardised or simulated patient within a defined amount of time (Van der Vleuten, 1996). The terms 'simulated' and 'standardised' patients have been used interchangeably in the literature. A layperson who has been trained to simulate a patient with a certain medical condition is often termed as a simulated patient (Cleland, Abe, \& Rethans, 2009). The term 'Standardised Patient' (SP), sometimes referred to as 'Expert Patient', can also be used to describe a simulated patient, someone 
who is a real patient with an actual condition but has been trained to portray his or her condition in a standardised manner (Barrows, 1993). Standardisation usually refers to the consistent presentation of responses including both verbal as well as behavioural responses by a standardised patient when prompted by a student or a candidate in a given simulated clinical situation (Adamo, 2003).

Standardisation and reliability are some of the key strengths of OSCE, however, these can only be ensured through careful planning and adequate training of station developers, examiners, and standardised patients. The scope of this review is to identify and comment on the best practices related to the development and implementation of OSCE as well as explore novel approaches to the use of OSCE in pharmacy education.

\section{Methods}

\section{Development of OSCE stations}

As with any assessment method, a blueprint should be developed to guide the selection of competencies that are required to be assessed (Newble, 2004). Blueprinting refers to the formal process of determining the examination content. For OSCEs, the blueprint considers the assessment content that has already been mapped with the overall curriculum and has adequate content validity (Khan et al., 2013). The blueprint then serves as a backbone to develop the stations. It should be ensured that the blueprint is in line with the overall programme outcomes and tailored to the institution by the assessment team. One such approach, as described by Mookherjee and authors (2013), is the development of a longitudinal blueprint that allows for progressive clinical skills assessment across the curriculum and programme. As per the developed blueprint, all stations are primarily developed by the pharmacy school's OSCE team which should include the lead and the pharmacy academic staff, with the input from the subject matter experts (Khan et al., 2013). The blueprint should then be periodically reviewed to ensure the internal structure validity by closely examining the psychometric measures encompassing inter-item correlations, examination difficulty, and score reliability (Yazbeck Karam et al., 2018). The OSCE lead also has the overall responsibility of managing the development, organisation, and conducting of the OSCE (Mccoy \& Merrick, 2001).

\section{OSCE checklists}

A checklist is a list of statements that are used to describe the actions expected from the students at each station (Heidi, 2008). The checklists are prepared by the OSCE team to ensure that they are aligned with the content and outcomes being assessed (Khan et al., 2013). The analytical checklist can be binary, where the examiners are required to choose between a yes or a no, or employ a rating scale consisting of a range of points. Binary checklists only allow the examiners to assess whether the students performed the task leaving no room for discriminating between the lower or higher levels of performance (Wallace, Rao, \& Haslam, 2002). Binary checklists originally introduced by Harden (1975) were understood to have the ability to provide an objective assessment of a student's performance and were perceived to yield greater inter-rater reliability. Van der Vleuten and authors suggested that reliability is the measure of an agreement between two examiners assessing the same student (Van der Vleuten, Norman, \& De Graaff, 1991). In other words, if the score of two examiners for the same student is similar, the assessment could be considered objective. However, others have challenged that objectivity does not always translate into greater reliability (Wilkinson et al., 2003). Achieving objectivity is not dependent on the checklists, rather it requires diligent examiners. Considering the variation in the expertise of examiners used in the OSCEs, it is useful to employ an analytical checklist with a rating scale consisting of a range of points to allow examiners to assess students based on the extent of the activities performed by the students at the station (Wallace, Rao, \& Haslam, 2002).

In addition to using the analytical checklists which are task-specific, the examiners are sometimes also required to use a global checklist with a rating scale of 1-5 points to assess the overall performance of the student (Rothman et al., 1996). There is growing evidence to suggest that global checklists, when compared to analytical checklists, are associated with better inter-station reliability and better construct validity compared to analytical checklists alone (Turner \& Dankoski, 2008). Global checklists take a holistic view of the process and allow the examiners to assess the overall performance of the student at a station (Reznick et al., 1998). Such checklists help examiners to not only determine whether the task was performed by the student or not, but also allow them to judge the quality of the task performed at the station (Rothman et al., 1996). Furthermore, global checklists allow the examiners to assess the communication skills of students by taking into account their verbal and non-verbal 
expressions, their ability to empathise with patients, their degree of focus, logic, and coherence (Morgan, CleaveHogg \& Guest, 2001; Hodges \& Mcilroy, 2003). These checklists include the marks coupled with whether the task is performed by the student at the station and to what extent.

\section{Standard-Setting}

Standard-setting refers to a procedure that is conducted before OSCE to determine a cut-off score at which a candidate will pass or fail. The Norm-referenced and the criterion methods are the two commonly reported standard-setting procedures in the literature (Cizek, 2011; Geisinger, 2012; Prince, 2016;). The Norm-referenced or the relative method involves the determination of scores based on the relative scores of the students. Constructing standards based on peer scores indicates that the performance can differ from one cohort to the other suggesting that a weak student within a weaker cohort may potentially progress in an examination which he or she would have failed to progress if taken with a stronger group of students (Searle et al., 2012). Such methods of standard-settings are therefore not suited to competency examinations such as OSCEs where students are required to demonstrate that they possess the required set of skills and are safe to practice (Khan et al., 2013). In contrast to the Norm-referencing or the relative method, the criterion method, also known as the absolute method, aims to determine the cut-off scores based on the level of competence required from students in the context of the topic or the skill being assessed (Cizek, 2011). Such methods are therefore better suited to competency-based examinations such as OSCEs (Turnbull, 1989). The two commonly used criterion methods include Angoff (1971) and Ebel (1972). The Angoff method, more widely used in the context of OSCE, requires qualified experts to independently determine the probability of a borderline student performing a task correctly (Angoff, 1971). The panel members then hold discussions among themselves about their initial judgment and scores against each item before continuing with the next set of items. In addition to establishing cut-off scores and pass/fail decisions in the Angoff method, a certain percentage is also sometimes assigned to the students' performance in OSCEs which then contributes to their overall grade particularly in specialist pharmacy-practice modules (Kirton \& Kravitz, 2011).

\section{Piloting the stations}

Piloting of the stations helps the OSCE team identify any issues with their length or content and allows them to make any adjustments accordingly (Whelan, 1999). Any station with an inadequate length is then restructured and piloted again. Conducting a mock OSCE before the actual OSCEs sometimes helps pilot the stations (Abdelaziz et al., 2015). Furthermore, students can use this opportunity as a formative assessment to orientate themselves with the OSCE process as well as gain prompt and useful feedback on their performance from the examiners (Khan et al., 2013). However, since OSCEs are resource-intensive and require extensive planning, individual stations are also sometimes piloted within the summative OSCE circuit. In this situation, students are briefed about the inclusion of such stations prior to the OSCE and that their scores would have no bearing on students' overall scores.

\section{Running of the OSCE stations}

The OSCE stations are laid out in the format of a circuit in which each student is required to complete all the stations. The number of stations may vary depending on many factors such as the level of the module, year of students, competencies assessed, and the number of students (Abdelaziz et al., 2015). Students move from one station to the other after a specific time which has been agreed in the standard-setting following the piloting. The movement of students across the circuit is facilitated by using a pre-programmed computer timing software attached with the speakers which automatically announces the start and the end of the stations (Abdelaziz et al., 2015). In the absence of this simulation technology, the movement of students across the stations is managed manually with the help of a stopwatch by a designated staff member who ensures that the students move in the right direction through the circuit at the specified timing. Students are made aware of the timing of each station and the turnaround time for moving from one station to the other prior to the start of the OSCE (Abdelaziz et al., 2015).

Depending on the number of stations and the number of students, it may be feasible to conduct the OSCE in more than one parallel circuit (Rushforth, 2007). This may shorten the overall OSCE time; however, it requires more staff as examiners and simulated patients. Constructing the OSCE stations in separate rooms is useful as it offers more confidentiality and lower noise levels as opposed to using large rooms divided by temporary partitions into the stations and signposted with clear directions. It is also feasible to include one or more 'rest' stations among the 'active' stations. Rest station is referred to as the station 
where the student is not required to perform any activity and does not have to face any examiner or simulated patient (Rushforth, 2007). It allows the students to have a break between the stations. As the number of students included is proportional to the number of stations present in the OSCE circuit, rest stations provide an opportunity to include an additional student in the circuit if necessary (Humphris \& Kaney, 2001). It is important, however, that the rest stations are constructed in a place where students do not hear what is being said at the surrounding stations (Abdelaziz et al., 2015). The rest stations are clearly labelled to avoid any confusion among the students. Students should ideally be given a tour of the examination circuit prior to the start of the OSCE to make them familiar with the sequence of the stations as well as with the rest stations (Rushforth, 2007).

\section{Reliability}

An OSCE is considered reliable if it can produce consistent and reproducible results with minimal errors (Boursicot, 2010). In other words, the same results should be produced if the assessment were repeated with different examiners. The duration and number of the stations and variations within the examiners, together with the number of test stations that are being piloted, are some of the factors that can affect the reliability of results (Wakeford, 2001). Evidence suggests that increasing the number of stations with an adequate duration is associated with increased reliability and can make the students' performance generalisable (Roberts, 2006; Swanson, Norman, \& Linn 1995). Epstein (2007) recommends using 14-18 stations each with a length of five to ten minutes to achieve optimal reliability.

Consistent marking by trained examiners is another factor that plays an important role in maintaining the reliability of OSCEs (Cunnington, Neville, \& Norman, 1997). The reliability of OSCE scores produced by the assessors or examiners is not only dependent on their uniform and consistent scoring but also relies on their clinical expertise in the context of skills being assessed. It is, therefore, important to match the skills of examiners with the content of the OSCE station (Azim et al., 2019). For example, it would be useful to employ experienced clinical pharmacists to assess pharmacy students at patient-facing stations. However, regardless of the examiners' expertise and experience, adequate training should be provided to them to ensure consistency in marking across all the examiners. Furthermore, with the involvement of many examiners and with varying levels of their expertise, it becomes critical to set clear standards and inform them of their expectations as examiners (Azim et al., 2019). Evidence suggests that the provision of training to examiners minimises the variation in their scoring which can then lead to higher reliability of results (Newble, Hoare, \& Sheldrake, 1980). Therefore, in addition to conducting examiner briefing on the day of the examination before the start of the OSCE, training sessions are arranged for examiners at least a week in advance to brief them about their responsibilities as examiners. New examiners with limited prior experience are usually utilised during a mock or piloting phase to make them familiar with the process (Azim et al., 2019).

Inconsistency among simulated patients is another factor that can influence the reliability of OSCE scores. Simulated patients who are inconsistent in their approach towards the students have a negative impact on the reliability of the results (Smee, 2003). Although the simulated patients are often briefed prior to the start of the OSCE, high stake examinations such as OSCEs require the provision of extensive training to the simulated patients in advance of the examination to help them role-play in considerably complex patient scenarios (McLaughlin et al., 2006). The literature seems to debate the adequate duration of the training which a simulated patient should receive before role-playing in OSCE. Shumway and Harden (2003) estimate that it may require an average of 15 hours to sufficiently train a simulated patient. The duration may, however, vary given the type of role and prior experience of the simulated patient (McLaughlin et al., 2006). Upon the completion of training, the performance of each simulated patient is independently evaluated by qualified experts to ensure he or she is qualified enough to be included in an OSCE (Williams, 2004). Newly qualified simulated patients, similar to the new examiners, are usually utilised to role-play in mock assessments to give them adequate exposure prior to the actual OSCE.

Having a group of simulated and trained patients on board is also advantageous to other healthcare OSCEs. If a university has employed a certain group of simulated and trained patients, also called 'expert patient group', it is utilised by all healthcare schools within the university for their performance-based activities and assessments such as OSCEs. However, in the absence of simulated and trained patients, the examiner at each station helps roleplay the patient simultaneously (Rushforth, 2007).

\section{Validity}

Any assessment tool is valid if it can assess what it has been designed to assess. Three facets of validity have traditionally been reported in the literature. These include 
face validity, construct validity, and impact validity (Wakeford, 2001). In the past, these were considered as three separate units of validity. However, more recently construct validity has been understood to encompass all types of validities (Downing, 2010). The American Educational Research Association (1999) has outlined various sources of evidence on which the construct validity is dependent. These include: the evidence to show that the assessment tool has been mapped to the curriculum (blueprinting), the evidence to demonstrate that it accurately records students' responses to the items being assessed (checklists), the evidence to show that the tool is reliable; and the evidence to demonstrate that the consequences of passing or failing the examinations are justified (Khan \& Ramachandran, 2012). The validity of OSCE stations is established by using criterion-based standard-setting methods as described above as well as by examining the psychometric measures both at the station level and across the entire OSCE (Yazbeck et al., 2018).

A higher passing grade is usually applied to performancebased assessments in healthcare education such as OSCEs. OSCEs are designed to determine if a student is deemed safe to practice in any healthcare clinical setting (Rushforth, 2007). However, there is not much evidence to demonstrate what grade or mark could be considered appropriate for performance-based assessments which ensures that the student now possesses the required skills and is qualified to enter the clinical practice. It is therefore difficult to predict the passing criteria that reflect the safe practice.

\section{Feedback to students on their OSCE performance}

Many pharmacy schools employ a formative OSCE prior to the summative OSCE (Hadi et al., 2018). Formative OSCE not only helps pilot the stations, as discussed above, but also helps determine the feasibility of the OSCE process for the OSCE teams (Aeder et al., 2007). Moreover, formative OSCES also provide an opportunity for students to be familiar with the OSCE content and process prior to the actual OSCE as well as can reduce the assessmentrelated stress they may have for the actual OSCE. Timely feedback on student performance is an essential part of their learning. The OSCE teams and/or the relevant module coordinators arrange to provide feedback to the students following the formative OSCE, either individually or with general feedback to the whole group of students, to improve their performance in the actual OSCE (Rebel et al., 2018). As with feedback to students on any assessment, it should be quality student-centred feedback focusing on learning rather than marks (Gibbs \& Simpson,
2004). It is also ensured that there is sufficient time between the feedback from formative OSCE and the actual OSCE for students to reflect upon their performance, weaknesses, and strengths. Depending on the pharmacy programme and the level of students and resources, some pharmacy schools only employ either formative or summative OSCE followed by the provision of feedback to the students on their performance (Rebel et al., 2018). Such cases should, however, ensure that the students utilise the feedback they receive or reflect on their performance, for example by writing reflections in their portfolios.

\section{OSCE evaluation}

Evaluation of any assessment method should be an integral part of the school's assessment strategy (Pierre et al., 2004). Students are in the best position to evaluate how much an assessment contributes to their learning. Involving students in assessment evaluation and making them feel that their voice is heard and acted upon also provides them with an opportunity to feel ownership of the assessment process to some extent which leads to enhanced student engagement (Aeder et al., 2007). In the majority of the pharmacy schools, student evaluations include evaluation of the OSCE process by students which may encompass rating of the stations by students regarding 'ease of understanding written instructions at OSCE station', 'level of difficulty of the task at OSCE station', 'degree of learning gained from the competencies', degree of learning needed to accomplish the task at OSCE station', 'adequacy of time given to accomplish the task at each OSCE station' and 'appropriateness of reference material provided at OSCE station' (Awaisu et al., 2010). Students' perceptions regarding the quality of their learning are also sometimes captured either by a survey questionnaire or by inviting open-ended written comments from the students after they have completed the OSCE (Awaisu et al., 2007).

OSCE evaluation by the academic staff involved or the examiners as well as by the simulated patients is equally important (Rushforth, 2007). This is achieved by debriefing with all the personnel involved immediately after the OSCE, a survey questionnaire, or by inviting open-ended written comments from them (Awaisu et al., 2007; Awaisu et al., 2010). These student and staff evaluations are then used by the faculty to significantly improve their teaching content and assessment strategies (Angelo \& Cross, 2018). The authors have learned from this experience that showing students how their evaluations have been used to improve the modules and assessments increases their 
motivation and engagement in the learning and assessment process.

\section{Discussion}

\section{OSCE in comparison with other assessment methods}

There are certain skills and competencies which can be best assessed by OSCE only, such as performance-based tasks and communication skills, however, this assessment method can be very daunting for the students (Rushforth, 2007). Awaisu and authors asked their pharmacy students to compare OSCE with other assessment methods (Awaisu et al., 2010). Most of the students rated OSCE as the most difficult assessment method when compared to multiplechoice questions and essay questions. However, they rated it as the method from which they learned most as compared to the other assessment methods. Despite this, the students preferred OSCE over the other assessment methods. It is a good practice for pharmacy curriculum developers to map the knowledge, skills, and competencies which are assessed by different assessment methods, including the OSCEs, across the pharmacy degree program (Kristina \& Wijoyo, 2018). This mapping evidence should then be accessible by the students to demonstrate how OSCEs contribute to their learning journey in the pharmacy school.

\section{Innovative approaches and the future}

Depending on the level of students and competencies being assessed, OSCE stations sometimes include a 'critical element' on certain stations (Hadi et al., 2018). A 'critical element' is a certain element at the station which must be addressed and failing to address or answer that element results in a fail or zero mark for the whole station (Hadi et al., 2018). The elements which can lead to patient harm when not addressed, are generally considered as critical elements and this approach can be best used to train the students on patient safety (Hsieh, Cheng, \& Chen, 2014). Using this approach in OSCEs stresses the value of patient safety in the students before they enter the practice. Additionally, adapting the OSCE based on local culture and language in order to mimic the real-life clinical practice as closely as possible in different countries, helps better equip the students for local practice. For example, Hadi and authors, who described their experience of conducting OSCE in one of the pharmacy schools in Saudi Arabia, reported having included some stations in the Arabic language to closely mimic the real-world scenarios (Hadi et al., 2018).
Based on the scenarios, some stations may not allow adequate time to cover all the assessment points at one single station (Rushforth, 2007). Developing coupled stations (also referred to as 'couplet stations' or 'linked stations') addresses this issue in which the scenario is extended or continued from one station to the subsequent station (Hodges et al., 2002). This, however, requires meticulous logistic planning. This approach has been used in OSCEs in medical education (Pugh \& Smee, 2013) and undoubtedly can also be adopted for OSCEs in pharmacy education. Since planning and conducting OSCE is a very laborious task for OSCE teams and requires a collective effort of staff and simulated patients, managing the involved personnel sometimes can be very challenging. Utilising the higher-level students, interns, or residents as second examiners or even as simulated patients at the OSCE stations can be attempted. Again, this approach has been adopted for OSCE in medical education (Fouad et al., 2019) and undoubtedly can be taken for OSCEs in pharmacy education.

Various modified approaches have now been introduced in this COIVD-19 era and some of them may continue through to the post-COVID-19 era (Ali, 2020). Since the literature regarding these modified approaches is still emerging, the inclusion of the best practices related to these modified approaches was deemed beyond the scope of this review. Future reviews should identify these approaches and highlight their pros and cons for educators.

\section{Conclusion}

OSCEs are designed to assess a range of clinical and communication skills, yet they are resource-intensive and require extensive planning. This review identifies the best practices related to the development and implementation of OSCE and highlights the pros and cons of various approaches. Attention must be paid to meticulous details from developing the OSCE stations and their piloting to the implementation of OSCE and its evaluation. It must be considered as an opportunity to provide ample feedback to the students to improve their learning. OSCE evaluations should be used for continuous improvement of the learning and teaching content and the OSCE process. Novel OSCE approaches applied in medical education can be adopted and tested in pharmacy education to further improve the quality of the OSCE process and better train pharmacy students for safe future practice. 


\section{Acknowledgements}

None

\section{Declaration of interest statement}

None

\section{Funding}

None

\section{Data availability statement}

Data sharing does not apply to this article as no new data were created or analysed in this study.

\section{References}

Abdelaziz, A., Hany, M., Atwa, H., Talaat, W., \& Hosny, S. (2015). Development, implementation, and evaluation of an integrated multidisciplinary Objective Structured Clinical Examination (OSCE) in primary health care settings within limited resources. Medical Teacher, 38(3), 272-279. https://doi.org/ 10.3109/0142159x.2015.1009018

Adamo, G. (2003). Simulated and standardized patients in OSCEs: Achievements and challenges 1992-2003. Medical Teacher, 25, 262-270. https://doi.org/10.1080/0142159031000100300

Aeder L., Altshuler L., Kachur E., Barrett S., Hilfer A., Koepfer S., Schaeffer H., Shelov S.P. (2007). The "Culture OSCE" - Introducing a Formative Assessment into a Postgraduate Program. Education for Health, 20(1), 11

Ali, M. (2020). What now and what next? The new era of OSCE. Pharmacy Education, 20, 56-58. https://doi.org/10.46542/pe. 2020.202.5658

American Educational Research Association. (1999). Standards for educational and psychological testing. Washington, DC: American Educational Research Association.

Angelo, T.A., \& Cross, K.P. (2018). Classroom assessment techniques: A handbook for college teachers. Vancouver, B.C.

Angoff, W.H. (1971). Scales, norms and equivalent score. In Educational measurement, edited by Thorndike RL. 2nd ed. Washington DC: American Council on Education.
Awaisu, A., Abd Rahman, N.S., Nik Mohamed, M.H., Bux Rahman, Bux., S.H., \& Mohamed Nazar, N.I. (2010). Malaysian pharmacy students' assessment of an objective structured clinical examination (OSCE). American Journal of Pharmaceutical Education, 74(2), 34. https://doi.org/10.5688/aj740234

Awaisu, A., Mohamed, M.H., \& Al-Efan, Q.A. (2007). Perception of pharmacy students in Malaysia on the use of objective structured clinical examinations to evaluate competence. American Journal of Pharmaceutical Education, 71(6), 118. https://doi.org/10.5688/aj7106118

Azim, A., Kumar, A., Krishnamurthy, K., Ojeh, N., Adams, O., \& Sa, B. (2019). An evaluative study of objective structured clinical examination (OSCE): students and examiners perspectives. Advances in Medical Education and Practice, 10, 387-397. https://doi.org/10.2147/amep.s197275

Barrows, S.H. (1993). An overview of the uses of standardized patients for teaching and evaluating clinical skills. Academic Medicine, 68, 443-451. https://doi.org/ 10.1097/00001888-199306000-00002

Boursicot, K.A.M. (2010). Structured assessments of clinical competence. British Journal of Hospital Medicine, 71, 342-344. https://doi.org/10.12968/hmed.2010.71.6.48450

Chisnall, B., Vince, T., Hall, S., \& Tribe, R. (2015). Evaluation of outcomes of a formative objective structured clinical examination for second-year UK medical students. International Journal of Medical Education, 6, 76-83. https://doi.org/10.5116/ ijme.5572.a534

Cizek, G.J. (Ed.). (2011). Setting Performance Standards: Foundations, Methods, and Innovations (2nd ed.). Routledge. https://doi.org/10.4324/9780203848203

Cleland, J.A., Abe, K., \& Rethans, J.J. (2009). The use of simulated patients in medical education: AMEE Guide No 42. Medical Teacher, 31, 477-486. https://doi.org/10.1080/01421590903002821

Cunnington, J.P.W., Neville, A.J., \& Norman, G.R. (1997). The risks of thoroughness: reliability and validity of global ratings and checklists in an OSCE. Advances in Health Sciences Education: Theory and Practice, 1(3), 227-33. https://doi.org/10.1007/ BF00162920

Downing, S.M. (2010). Validity: Establishing meaning for assessment data through scientific evidence. St George's Advanced Assessment Course: London.

Ebel, R. (1972). Essentials of educational measurement. New Jersey, NJ: Prentice-Hall.

Epstein, R.M. (2007). Assessment in Medical Education. The New England Journal of Medicine, 356, 387-396. https://doi.org/ 10.1056/NEJMra054784

Fouad, S., Gouda, E., Abdel Nasser, A., \& Kamal, D. (2019). Perception of students, staff and simulated patients towards 
objective structured clinical examination (OSCE). Education in Medicine Journal, 11, 27-42. https://doi.org/10.21315/ eimj2019.11.2.4

Geisinger, K.F. (2012). Norm- and criterion-referenced testing. In Cooper, H., Camic, P.M., Long, D.L., Panter, A.T., Rindskopf, D., \& Sher K.J. (Eds.), APA handbooks in psychology: APA handbook of research methods in psychology. American Psychological Association. https://doi.org/10.1037/13619-020

Gibbs, G., \& Simpson, C. (2004). Conditions under which assessment supports students learning. Learning and Teaching in Higher Education, (1), 3-31.

Hadi, M.A., Ali, M., Haseeb, A., Mohamed, M., Elrggal, M.E, \& Cheema, E. (2018). Impact of test anxiety on pharmacy students' performance in Objective Structured Clinical Examination: a cross-sectional survey. International Journal of Pharmacy Practice, 26(2), 191-194. https://doi.org/10.1111/ijpp.12389

Harden, R.M., Stevenson, M., Downie, W.W., \& Wilson, G.M. (1975). Assessment of Clinical Competence using Objective Structured Examination. British Medical Journal, 1, 447-451. https://doi.org/10.1136/bmj.1.5955.447

Harden, R., \& Gleeson, F. (1979). Assessment of clinical competence using an objective structured clinical examination (OSCE). Medical Education, 13, 41-54.

Heidi, S. (2008). What does an OSCE checklist measure?. Essays and Commentaries, 40(8), 589-591.

Hodges, B., Hanson, M., McNaughton, N., Regehr, G., \& University of Toronto Psychiatric Skills Assessment Project (2002). Creating, monitoring, and improving a psychiatry OSCE: a guide for faculty. Academic Psychiatry, 26(3), 134-161. https://doi.org/ 10.1176/appi.ap.26.3.134

Hodges, B., \& Mcilroy, J.H. (2003). Analytic global OSCE ratings are sensitive to level of training. Medical Education, 37, 10121016. https://doi.org/10.1046/j.1365-2923.2003.01674.x

Hsieh, M., Cheng, W., \& Chen, T. (2014). Objective structured clinical examination (OSCE) including critical simulation: Evaluation of medical student competence. Tzu Chi Medical Journal, 26(1), 40-43. https://doi.org/10.1016/j.tcmj. 2013.08.001

Humphris, G.M., \& Kaney, S. (2001). Examiner fatigue in communication skills objective structured clinical examination. Medical Education, 35, 444-449. https://doi.org/10.1046/j. 1365-2923.2001.00893.x

Khan, K., \& Ramachandran, S. (2012). Conceptual Framework for Performance Assessment: Competency, Competence and Performance in the Context of Assessments in Healthcare Deciphering the Terminology. Medical Teacher, 34(11), 920-928. https://doi.org/10.3109/0142159X.2012.722707
Khan, K.G., Sankaranarayanan, R., \& Piyush, P. (2013). The Objective Structured Clinical Examination (OSCE): AMEE Guide No. 81. Part II: Organisation \& Administration. Medical Teacher, 35(9), https://doi.org/10.3109/0142159X.2013.818634

Kirton, S.B., \& Kravitz, L. (2011). Objective Structured Clinical Examinations (OSCEs) compared with traditional assessment methods. American Journal of Pharmaceutical Education, 75(6), 111. https://doi.org/10.5688/ajpe756111

Kristina, S., \& Wijoyo, Y. (2018). Assessment of pharmacy students' clinical skills using objective structured clinical examination (OSCE): A Literature Review. Systematic Reviews in Pharmacy, 10(1), 55-60.

Mccoy, J.A., \& H.W, Merrick, H.W, eds. (2001). The Objective Structured Clinical Examination. Association for Surgical Education. Springfield, IL.

McLaughlin, K., Gregor, L., Jones, A., \& Coderre, S. (2006). Can standardized patients replace physicians as OSCE examiners?. British Medical Coucil Medical Education, 6(12), 1-5. https:// doi.org/10.1186/1472-6920-6-12

Mookherjee, S., Chang, A., Boscardin, C.K., Hauer, K.E. (2013). How to develop a competency-based examination blueprint for longitudinal standardized patient clinical skills assessments. Medical Teacher, 35, 883-990. https://doi.org/ 10.3109/0142159X.2013.809408

Morgan, P.J., Cleave-Hogg, D., \& Guest, C.B. (2001). A comparison of global ratings and checklist scores from an undergraduate assessment using an anesthesia simulator. Academic Medicine, 76, 1053-1055. https://doi.org/10.1097/00001888-200110000-00016

Newble, D.I., Hoare, J., \& Sheldrake, P.F. (1980). The selection and training of examiners for clinical examinations. Medical Education, 14, 345-349. https://doi.org/10.1111/j. 1365-2923.1980.tb02379.x

Newble, D. (2004). Techniques for measuring clinical competence: Objective structured clinical examinations. Medical Education, 38, 199-203. https://doi.org/10.1111/j. 1365-2923.2004.01755.x

Pierre, R., Wierenga, A., Barton, M., Branday, J., \& Christie, C. (2004). Student evaluation of an OSCE in paediatrics at the University of the West Indies, Jamaica. British Medical Council Medical Education, 4(22), 1-7. https://doi.org/ 10.1186/1472-6920-4-22

Prince, R. (2016). Predicting success in higher education: the value of criterion and norm-referenced assessments. Practitioner Research in Higher Education, 10(1), 22-38.

Rebel, A., Hester, D., DiLorenzo, A., McEvoy, M., \& Schell, R. (2018). Beyond the "E" in OSCE. Anesthesia Analgesia, 127(4), 1092-1096. https://doi.org/10.1213/ane.0000000000003317 
Reznick, R.K., Regehr, G., Yee, G., Rothman, A., Blackmore, D., \& Dauphinee, D. (1998). Process-rating forms versus task-specific checklists in an OSCE for medical licensure. Medical Council of Canada. Academic Medicine, 73. https://doi.org/ 10.1097/00001888-199810000-00058

Roberts, C., Newble, D., Jolly, B., Reed, M., \& Hampton, K. (2006). Assuring the quality of high-stakes undergraduate assessments of clinical competence. Medical Teacher, 28(6), 535-543. https:// doi.org/10.1080/01421590600711187

Rothman, A.I., Blackmore, D., Dauphinee, W.D. et al. (1996). The use of global ratings in OSCE station scores. Advanced Health and Science Education, 1, 215-219.

Rushforth, H. (2007). "Objective structured clinical examination (OSCE): Review of literature and implications for nursing education". Nurse Education Today, 27(5), 481-490. https:// doi.org/10.1016/j.nedt.2006.08.009

Searle, N.S., Teal, C.R., Richards, B.F., Friedland, J.A., Weigel, N.L., Hernandez, R.A., Lomax, J.W., Coburn, M., \& Nelson, E.A. (2012). A standards-based, peer-reviewed teaching award to enhance a medical school's teaching environment and inform the promotions process. Academic Medicine, 87(7), 870-876. https://doi.org/10.1097/ACM.0b013e3182584130

Shumway, J.M., \& Harden, R.M. (2003). The assessment of learning outcomes for the competent and reflective physician: AMEE Guide No. 25. Medical Teacher, 25, 569-584. https:// doi.org/10.1080/0142159032000151907

Smee, S. (2003). ABC of learning and teaching in medicine Skill based assessment. British Medical Journal, 326, 703-706. https://doi.org/10.1136/bmj.326.7391.703

Swanson, D.B, Norman, G.R, \& Linn, R.L. (1995). PerformanceBased Assessment: Lessons From the Health Professions. Educational Researcher, 24, 5-11. https://doi.org/ 10.3102/0013189X024005005

Toklu, H., \& Hussain, A. (2013). "The changing face of pharmacy practice and the need for a new model of pharmacy education". Journal of Young Pharmacists, 5(2), 38-40. https://doi.org/ 10.1016/j.jyp.2012.09.001

Turnbull, J.M. (1989). What is ... normative versus criterionreferenced assessment. Medical Teacher, 11(2), 145-50.

Turner, J.L, \& Dankoski, M.E. (2008). Objective Structured Clinical Exams: A Critical Review. Family Medicine, 40(8), 574-578.

Van der Vleuten, C.P., Norman, G.R., \& E, De Graaff. (1991). Pitfalls in the pursuit of objectivity: issues of reliability. Medical Education, 25(2), 110-8. https://doi.org/10.1111/j. 1365-2923.1991.tb00036.x

Van der Vleuten, C.P.M. (1996). The Assessment of Professional Competence: Developments, Research and Practical
Implications. Advances in Health Sciences Education, 1, 41-67. https://doi.org/10.1007/BF00596229

Wakeford, R. (2001). Principles of Assessment. In: Fry H, Ketteridge $S$ and Marshall S A Handbook for Teaching and Learning in Higher Education. Kogan Page Ltd, London.

Wallace, J., Rao, R., \& Haslam, R. (2002). Simulated patients and objective structured clinical examinations: review of their use in medical education. Advances in Psychiatric Treatment, 8(5), 342348. https://doi.org/10.1192/apt.8.5.342

Whelan, G.P. (1999). Educational commission for Foreign Medical Graduates - clinical skills assessment prototype. Medical Teacher, 21(2), 156-160. https://doi.org/ $10.1080 / 01421599979789$

Wilkinson, T.J., Frampton, C.M., Thompson-Fawcett, M., \& Egan, T. (2003). Objectivity in Objective Structured Clinical Examinations: Checklists Are No Substitute for Examiner Commitment. Academic Medicine, 78(2), 219-223. https:// doi.org/ 10.1097/00001888-200302000-00021

Williams, R.G. (2004). Have Standardized Patient Examinations Stood the Test of Time and Experience? Teaching and Learning in Medicine, 16, 215-222. https://doi.org/10.1207/ s15328015t $\mid m 1602 \_16$

Yazbeck Karam, V., Park, Y., Tekian, A., \& Youssef, N. (2018). Evaluating the validity evidence of an OSCE: results from a new medical school. British Medical Council Medical Education, 18, 313. https://doi.org/10.1186/s12909-018-1421-x 